Vol. 24, No. 3, Juli 2021, hlm. 558-570

p-ISSN: 1410-9344; e-ISSN: 2549-5631

WARTA LPM

homepage: http://journals.ums.ac.id/index.php/warta

\title{
Deteksi Faktor Risiko Penyakit Tidak Menular melalui Pos Pembinaan Terpadu Warga Sehat di Era Pandemi Covid-19
}

\author{
${ }^{1}$ Sulistyaningsih, ${ }^{1}$ Tri Hapsari Listyaningrum \\ ${ }^{1}$ Fakultas Ilmu Kesehatan Universitas 'Aisyiyah Yogyakarta \\ Email: ${ }^{1}$ sulistyaningsih@unisayogya.ac.id, ${ }^{2}$ trihapsari_listyaningrum@unisayogya.ac.id
}

\section{Article Info}

Submitted: 01 January 2021

Revised: 07 March 2021

Accepted: 09 April 2021

Published: 20 July 2021

Keywords: risk factors, non-communicable diseases, posbindu, pandemic Covid-19
Kata kunci: faktor risiko, penyakit tidak menular, posbindu, pandemi Covid-19

\section{Abstract}

Non-Communicable Diseases (NCD) are a serious threat during the Covid-19 pandemic because they are a vulnerable group. Most of the community's behavior is a risk factor for NCD, smoking habits, eating less fruits and vegetables, and less physical activity. RT 1 RW 7 Mejing Wetan, Ambarktawang, Gamping, Sleman have community groups that hold regular meetings every month, but there is no forum for NCD risk factor detection activities. The purpose of community service activities is to form Posbindu NCD so that it can help NCD risk factors so that they control NCD in the era of the Covid-19 pandemic. The implementation method of compiling the NCD risk factor detection book, outreach to community leaders, ordering the management, cadre training, preparing infrastructure and implementing Posbindu and monitoring sustainability. Activities have been carried out from August-December 2020. The results of the activity are trained cadres, a pocket book of NCD risk factors, the formation of the Posbindu WARAS (Warga Sehat) management, and the implementation of Posbindu with the Covid-19 health protocol so that it can provide NCD risk factors. The conclusion is that Posbindu NCD can be formed and can carry out activities regularly every month has successfully detected NCD risk factors.Posbindu cadres are asked to continue Posbindu activities regularly every month and can increase activities to increase community participation.

Abstrak
Penyakit Tidak Menular (PTM) menjadi ancaman yang serius pada
masa pandemi Covid-19 karena merupakan kelompok rentan.
Sebagian besar perilaku masyarakat merupakan faktor risiko PTM
yaitu kebiasaan merokok, kurang makan buah dan sayur, dan kurang
aktivitas fisik. Warga RT 1 RW 7 Mejing Wetan, Ambarktawang,
Gamping, Sleman telah memiliki kelompok-kelompok masyarakat
yang mengadakan pertemuan rutin tiap bulan, tetapi belum ada
forum kegiatan deteksi faktor risiko PTM. Tujuan kegiatan pengabdian
kepada masyarakat adalah membentuk Posbindu PTM agar dapat


mendeteksi faktor risiko PTM sehingga bermanfaat mengendalikan PTM pada era pandemi Covid-19. Metode pelaksanaan melalui penyusunan buku deteksi faktor risiko PTM, sosialisasi kepada tokoh masyarakat, pembentukan pengurus, pelatihan kader, persiapan sarana prasarana dan pelaksanaan Posbindu, serta monitoring keberlanjutan. Kegiatan dilaksanakan pada bulan Agustus-Desember 2020. Hasil kegiatan adalah kader terlatih, buku saku faktor risiko PTM, terbentuknya pengurus Posbindu WARAS (Warga Sehat), dan terlaksananya posbindu dengan protokol kesehatan Covid-19 sehingga dapat mendeteksi faktor risiko PTM. Simpulan bahwa Posbindu PTM dapat dibentuk dan dapat menyelenggarakan kegiatan secara rutin tiap bulan berhasil mendeteksi faktor risiko PTM. Bagi kader Posbindu disarankan untuk melanjutkan kegiatan Posbindu secara rutin tiap bulan dan dapat menambah kegiatan untuk meningkatkan partisipasi masyarakat.

\section{PENDAHULUAN}

Pandemi Covid-19 telah terjadi di seluruh negara di dunia dengan jumlah yang terus meningkat. Jumlah kasus terkonfirmasi sampai dengan 30 Desember 2020 adalah 80.453.105 orang, dengan kasus meninggal dunia 1.775 .776 orang (WHO, 2020). Faktor komorbid menjadi penyebab terbanyak kematian Covid-19 di Jawa Timur, Jawa Tengah, dan Sulawesi Selatan. Faktor komorbid antara lain Penyakit Tidak Menular (PTM) (Direktorat Jenderal Pencegahan dan Pengendalian Penyakit, 2019).

PTM menyebabkan 71\% kematian di dunia yang membunuh 36 juta jiwa per tahun pada tahun 2016. Kematian akibat PTM ini sebanyak $80 \%$ terjadi di negara berpenghasilan menengah dan rendah. Kematian yang disebabkan oleh PTM sebesar $73 \%$ diantaranya 35\% karena penyakit jantung dan pembuluh darah, $12 \%$ oleh penyakit kanker, $6 \%$ oleh penyakit pernapasan kronis, $6 \%$ karena diabetes, dan 15\% disebabkan oleh PTM lainnya (Direktorat Jenderal Pencegahan dan Pengendalian Penyakit, 2019).

Riskesdas tahun 2018 melaporkan bahwa terjadi peningkatan pada indikator-indikator kunci PTM yang tercantum dalam RPJMN 20152019, yaitu l) Prevalensi hipertensi penduduk usia lebih dari 18 tahun meningkat dari 25,8\% menjadi 34,1\%; 2) Prevalensi obesitas penduduk usia 18 tahun ke atas meningkat dari 14,8\%menjadi 21,8\%; dan 3) Prevalensi merokok penduduk usia $\leq 18$ tahun meningkat dari 7,2\% menjadi 9,1\% (Kementerian Kesehatan
Badan Penelitian dan pengembangan Kesehatan, 2018).

Peningkatan kasus PTM diperkirakan akan menambah beban masyarakat dan pemerintah, karena penanganannya membutuhkan biaya yang besar dan memerlukan teknologi tinggi. Hal ini dapat terlihat dari data Badan Penyelenggara Jaminan Sosial (BPJS) Kesehatan tahun 2017 sebanyak 10.801 .787 juta orang atau 5,7\% peserta Jaminan Kesehatan Nasional (JKN) mendapat pelayanan untuk penyakit katastropik dan menghabiskan biaya kesehatan sebesar 14,6 triliun rupiah atau 21,8\% dari seluruh biaya pelayanan kesehatan dengan komposisi peringkat penyakit jantung sebesar $50,9 \%$ atau 7,4 triliun, penyakit ginjal kronik sebesar $17,7 \%$ atau 2,6 triliun rupiah.

Keprihatinan terhadap peningkatan prevalensi PTM telah mendorong lahirnya kesepakatan tentang strategi global dalam pencegahan dan pengendalian PTM, khususnya di negara berkembang. PTM telah menjadi isu strategis dalam agenda SDGs 2030 sehingga harus menjadi prioritas pembangunan di setiap negara. Target global penyakit tidak menular adalah penurunan kematian 25\% akibat PTM di tahun 2025, melalui indikator (1) Respon nasional: cakupan pengobatan esensial dan teknologi PTM 80\%, Cakupan terapi farmakologis dan konseling 50\%, (2) Target regional: penurunan polusi rumah tangga $50 \%$, dan (3) Faktor risiko: peningkatan diabetes/ obesitas $0 \%$, penurunan tekanan darah tinggi $25 \%$, 
penurunan konsumsi tembakau 30\%, penurunan asupan garam $30 \%$, penurunan kurang aktivitas fisik $10 \%$, penurunan konsumsi alkohol 10\%. Pengendalian PTM juga dilakukan dengan upaya program Posbindu PTM yang dikembangkan oleh Kemenkes RI. Secara nasional desa/kelurahan yang melaksanakan kegiatan Posbindu PTM pada tahun 2019 sejumlah 50.657 desa/ kelurahan atau sebesar 60,79\% (Kementerian Kesehatan Republik Indonesia, 2020). Hasil evaluasi Posbindu ini masih terdapat hal yang perlu ditingkatkan dalam input yaitu sumber daya manusia, pendanaan, sarana dan prasarana yang belum merata, pada segi proses Posbindu telah dilakukan secara rutin tetapi kualitas dari pelayanannya masih kurang memadai dan evaluasi output dan outcome terlihat bahwa Posbindu PTM belum mencapai target dan outcome-nya untuk mengendalikan PTM juga tidak tercapai (Mahdur \& Sulistiadi, 2020).

PTM yang menempati urutan pertama pada sepuluh besar penyakit di DIY tahun 2019 berdasarkan surveilens terpadu penyakit adalah hipertensi (Dinas Kesehatan Daerah Istimewa Yogyakarta, 2020). Jumlah kasus hipertensi tahun 2019 di Kabupaten Sleman yang mendapat pelayanan kesehatan sesuai standar adalah $80,71 \%$, sedangkan kasus diabetes melitus yang mendapat pelayanan kesehatan sesuai standar adalah 82,64 \%. Skrining kesehatan yang dilakukan di Kabupaten Sleman dilakukan melalui posbindu, baik Posbindu masyarakat maupun Posbindu institusi. Pada tahun 2019 terdapat 486 posbindu yang terdiri dari 391 Posbindu masyarakat dan 95 Posbindu institusi. Di Kecamatan Gamping terdapat 29 Posbindu PTM (Dinas Kesehatan Kabupaten Sleman, 2020).

Berdasarkan laporan kegiatan Kuliah Kerja Nyata (KKN) mahasiswa Universitas 'Aisyiyah Yogyakarta yang dilaksanakan pada tahun 2019 di Desa Ambarketawang, Gamping, Sleman khususnya di Pedukuhan Mejing Wetan terdapat kasus hipertensi 41 orang (65\%), penyakit jantung 7 orang (11\%), dan diabetes melitus 3 orang (5\%). Jumlah kasus yang paling tinggi adalah di RT 1 RW 7 dan terdapat 2 (dua) orang yang meninggal karena serangan strok serta terdapat 2 (dua) keluarga dengan gangguan jiwa. Faktor risiko yang ada adalah kebiasaan merokok, kurang makan buah dan sayur, kurang aktivitas fisik. Berdasarkan penilaian indeks kesehatan keluarga, 22\% keluarga termasuk keluarga prasehat. Mahasiswa KKN telah melakukan penyuluhan hipertensi, senam hipertensi dan pemeriksaan keseimbangan, flexibilitas, asam urat, dan gula darah.

Jumlah penduduk RT 1 RW 7 Mejing Wetan adalah 127 orang, dengan jumlah kepala keluarga 49 orang. Sebagian besar penduduk usia berisiko PTM (83\%), pekerjaan penduduk pegawai swasta (21\%), pendidikan lulusan SMA (35\%), dan Perguruan Tinggi (16\%). Kelompokkelompok masyarakat yang dapat diberdayakan untuk pengendalian PTM, antara lain pertemuan rutin kepala keluarga tiap bulan (hari Sabtu pekan I), pertemuan rutin ibu-ibu tiap bulan (setiap hari Minggi pekan I), Kelompok Wanita Tani (KWT), Kelompok Jemparingan, Kelompok Pengajian Amanah tiap hari Jumat, dan Kelompok Remaja Masjid. Posyandu Lansia telah diselenggarakan di RT 9 setiap tanggal 19, tetapi lokasinya cukup jauh dari RT 1. Belum ada Posbindu PTM di RT 1 maupun Mejing Wetan. Pertemuan yang dilakukan secara rutin di RT 1 mempunyai potensi besar untuk dilakukan kegiatan deteksi faktor risiko PTM, sehingga dapat dilakukan pengendalian dini terhadap PTM.

RT 1 RW 7 Mejing Wetan memiliki 1 (satu) orang kader kesehatan, tetapi belum dilatih untuk deteksi faktor risiko PTM. Akibatnya masalah yang muncul belum semua warga RT 1 Mejing Wetan belum dapat mendeteksi dini faktor risiko PTM secara rutin. Berdasarkan analisis situasi, masalah dan potensi yang dimiliki, maka tujuan kegiatan pengabdian masyarakat ini adalah membentuk Posbindu PTM agar dapat mendeteksi faktor risiko PTM sehingga bermanfaat mengendalikan PTM pada era pandemi Covid-19.

\section{METODE}

Metode pendekatan untuk menyelesaikan permasalahan penyakit tidak menular pada RT 1 RW 7 Pedukuhan Mejing Wetan adalah Pemberdayaan Masyarakat untuk pengendalian faktor risiko PTM melalui pembentukan Posbindu Dasar PTM. Program ini dilaksanakan dengan kegiatan sebagai berikut. 
a. Penyusunan materi pegangan kader kesehatan Posbindu PTM yang berisi pedoman teknis pelaksanaan Posbindu PTM. Materi dikembangkan dari Buku Petunjuk Teknis Pos Pembinaan Terpadu Penyakit Tidak Menular (Posbindu PTM) (Kemenkes RI, 2012) dan Pedoman Manajemen PTM (Direktorat Jenderal Pencegahan dan Pengendalian Penyakit Kemenkes RI, 2019). Kegiatan ini dilaksanakan bulan Agustus 2020.

b. Penyusunan Buku Saku Pengendalian Faktor Risiko Penyakit Tidak Menular yang mengacu pada buku monitoring faktor risiko PTM (Kementerian Kesehatan Republik Indonesia, 2013). Kegiatan ini dilaksanakan bulan Agustus 2020.

c. Persiapan sarana prasarana Posbindu Dasar PTM dengan protokol kesehatan pencegahan penularan Covid-19, yaitu sebagai berikut.

1) Tensimeter digital :2

2) Alat ukur tinggi badan :2
3) Alat ukur lingkar perut :2

4) Timbangan berat badan :2

5) Thermo gun : 2

6) Hand sanitizer

Kegiatan ini dilaksanakan pada bulan September 2020.

a. Sosialisasi Posbindu Dasar PTM kepada Ketua RW, pengurus RT dan tokoh masyarakat yang dilaksanakan pada tanggal 22 September 2020 di pendapa rumah Ketua RT 1.

b. Pembentukan pengurus Posbindu Dasar PTM atas nama Posbindu WARAS (Warga Sehat) Mejing Wetan setelah selesai acara sosialisasi Posbindu Dasar PTM tanggal 22 September 2020 .

c. Pelatihan kader kesehatan Posbindu Dasar PTM yang dilaksanakan pada tanggal 23 September 2020.

Materi Pelatihan Kader/Pelaksana Posbindu PTM, yaitu:

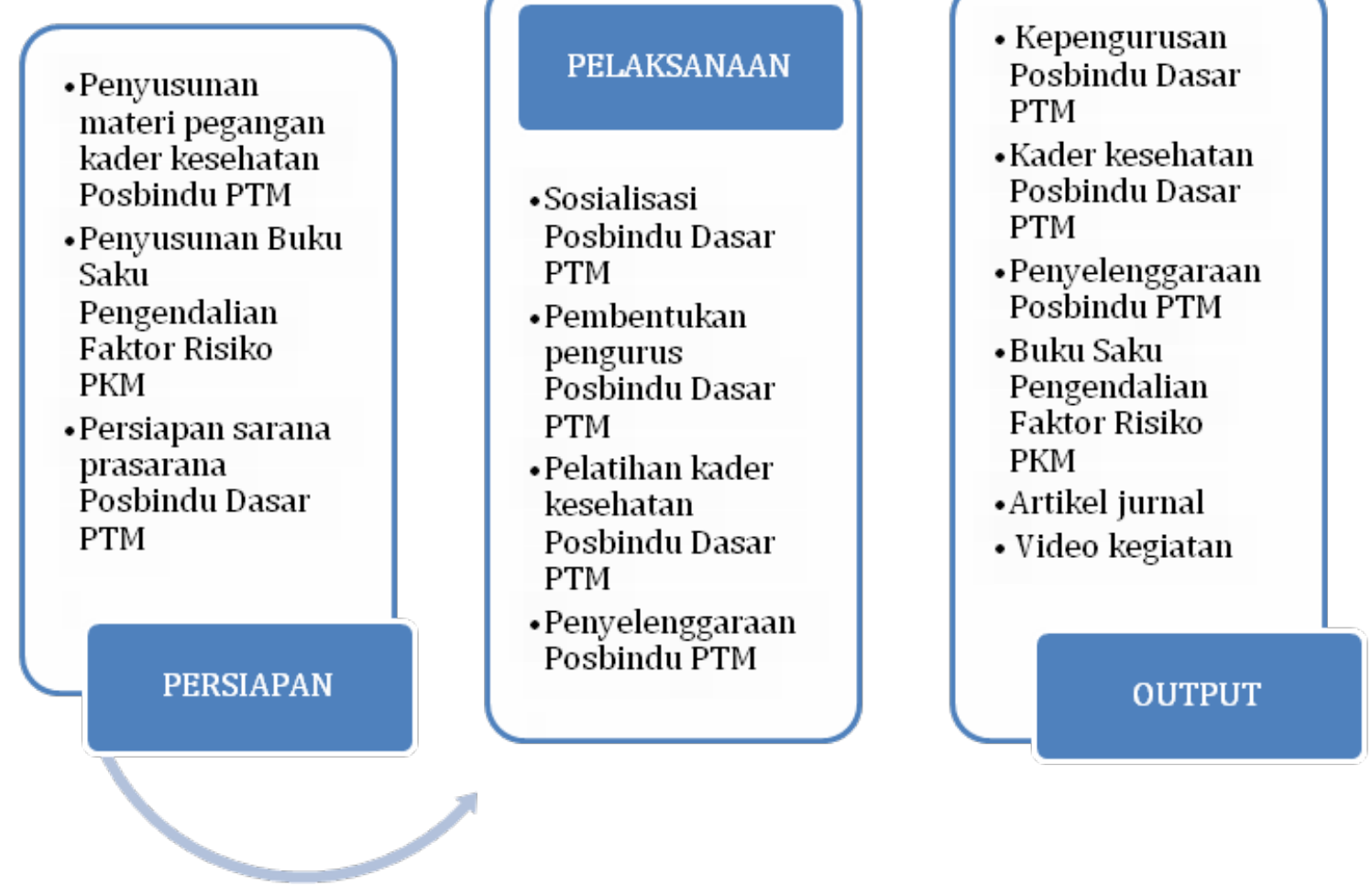

Gambar 1. Alur Metode Pelaksanaan Kegiatan Pengabdian Masyarakat Pembentukan Posbindu WARAS Mejing Wetan Ambarketawang, Gamping, Sleman Tahun 2020 
1) PTM dan Faktor Risiko

2) Posbindu PTM dan pelaksanaannya

3) Tahapan kegiatan Posbindu PTM (Lima Meja)

4) Cara pengukuran Berat Badan, Tinggi Badan, Lingkar perut, IMT, tekanan darah

5) Pencatatan Faktor Risiko PTM

6) Konseling, edukasi, dan tindak lanjut lainnya

7) Rujukan dan respon cepat sederhana

d. Penyelenggaraan Posbindu PTM pertama kali dilaksanakan pada tanggal 4 Oktober 2020 di lapangan Jemparingan RT 1.

Kegiatan tersebut terdiri dari:

1) Pemeriksaan suhu dengan menggunakan thermo gun.

2) Pemakaian hand sanitizer.

3) Registrasi Pemberian nomor kode/ urut yang sama serta pencatatan ulang hasil pengisian Buku Saku FR-PTM.

4) Pengukuran TB, BB, IMT, Lingkar Perut

5) Pemeriksaan tekanan darah

6) Pemeriksaan laboratorium

7) Identifikasi faktor risiko PTM, Konseling/Edukasi, serta tindak lanjut lainnya

e. Pendampingan penyelenggaraan Posbindu dilaksanakan selama enam bulan (November 2020 s.d. April 2021) untuk mengetahui konsistensi pelaksanaan Posbindu PTM.
Alur pelaksanaan program kegiatan ini dapat dilihat pada gambar 1 .

\section{HASIL DAN PEMBAHASAN}

Pengabdian masyarakat diawali dengan membuat materi pegangan kader kesehatan dan buku saku Posbindu PTM. Selanjutnya tim pengabdian masyarakat Universitas 'Aisyiyah Yogyakarta melakukan sosialisasi Posbindu Dasar PTM kepada Ketua RW, pengurus RT, dan tokoh masyarakat pada hari Sabtu, 26 September 2020 pukul 19.30-21.00 WIB di halaman pendopo rumah Ketua RT 1 RW 07 Mejing Wetan. Sosialisasi dihadiri 22 orang. Berikut ini foto dokumentasi pelaksanaan kegiatan yang dilaksanakan berupa pemaparan materi terkait dengan Penyakit Tidak Menular dan pentingnya pembentukan Posbindu, serta diskusi tentang pembentukan kader kesehatan PTM di Posbindu PTM Mejing Wetan, Ambarketawang, Gamping, Sleman.

Setelah sosialisasi, dilakukan pengukuran sikap tentang pembentukan Posbindu melalui pengisian kuesioner, dengan hasil dapat dilihat pada tabel 1.

Hasil pengkajian dari sikap masyarakat tentang pembentukan Posbindu PTM diperoleh rata rata 3,4 dari skala 4 yang dapat diartikan bahwa masyarakat mendukung terbentunya Posbindu tersebut. Skor tertinggi terpadat dalam 2 poin pertanyaan yaitu Posbindu PTM perlu dibentuk karena sangat bermanfaat untuk memantau kesehatan warga dan sasarannya

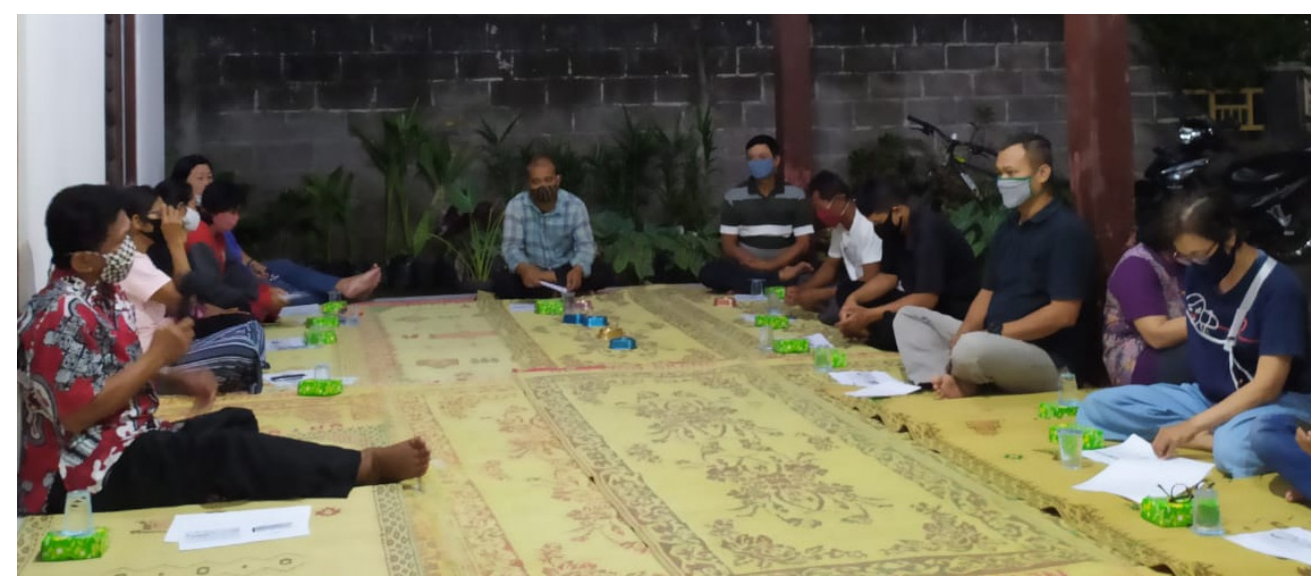

Gambar 2. Sosialisasi tentang Posbindu PTM kepada Tokoh Masyarakat Mejing Wetan Tanggal 22 September 2020 
Tabel 1. Sikap Masyarakat tentang Posbindu PTM Mejing Wetan, Ambarketawang, Gamping, Sleman Bulan September 2020

\begin{tabular}{llcl}
\hline No. & \multicolumn{1}{c}{ Pernyataan } & $\begin{array}{c}\text { Skor } \\
\text { (skala 1-4) }\end{array}$ & \multicolumn{1}{c}{ Keterangan } \\
\hline 1. $\begin{array}{l}\text { Posbindu PTM perlu dibentuk karena sangat bermanfaat } \\
\text { untuk memantau Kesehatan warga. }\end{array}$ & 3,7 & Sangat mendukung \\
2. $\begin{array}{l}\text { Posbindu PTM perlu dibentuk karena dapat monitor risiko } \\
\text { PTM warga. }\end{array}$ & 3,3 & Mendukung \\
3. $\begin{array}{l}\text { Posbindu PTM perlu dibentuk karena sasarannya tidak } \\
\text { hanya untuk lansia tetapi juga untuk usia produktif. }\end{array}$ & 3,7 & Sangat mendukung \\
4. $\begin{array}{l}\text { Posbindu PTM dapat dilaksanakan bersamaan dengan } \\
\text { kegiatan di masyarakat (arisan/rapat rutin/lain-lain) }\end{array}$ & 3,6 & Sangat mendukung \\
5. $\begin{array}{l}\text { Posbindu PTM dilaksanakan tersendiri, tidak bersamaan } \\
\text { dengan kegiatan lainnya. }\end{array}$ & 2,4 & Kurang mendukung \\
6. Perlu dibentuk kader khusus Posbindu PTM. & 3,7 & Sangat mendukung \\
7. $\begin{array}{l}\text { Masyarakat dapat menyediakan sarana prasarana secara } \\
\text { mandiri/ swadaya untuk pelaksanaan Posbindu PTM. }\end{array}$ & 3,1 & Mendukung \\
8. Perlu kerja sama dengan pihak lain untuk melaksanakan & 3,6 & Sangat mendukung \\
$\quad \begin{array}{l}\text { Posbindu PTM. } \\
\text { Rerata }\end{array}$ & 3,4 & Mendukung \\
\hline
\end{tabular}

tidak hanya untuk lansia tetapi juga untuk usia produktif dengan skor keduanya 3,7 yaitu sangat mendukung. Sikap tentang Posbindu PTM dilaksanakan tersendiri, tidak bersamaan dengan kegiatan lainnya memperoleh skor terendah yaitu 2,4 dengan kriteria kurang mendukung. Masyarakat menyarakan untuk pelaksanaan Posbindu PTM dilaksanakan bersamaan dengan kegiatan arisan rutin ibu-ibu setiap hari Minggu pekan pertama pukul 09.00 WIB di lapangan Jemparingan Mejing Wetan yang secara rutin sudah diselenggarakan oleh masyarakat.

Selain hasil pengisian kuesioner, dukungan sikap warga ditunjukkan dengan terbentuknya pengurus Posbindu dengan nama Posbindu WARAS (Warga Sehat). Pengurus Posbindu terdiri dari Ketua, Sekretaris, Bendahara, Bagian Perlengkapan, Bagian Humas, Kader, dan Konselor.

Persiapan sarana prasarana Posbindu Dasar PTM dilakukan dengan diskusi bersama warga sehingga disepakati bahwa diadakan pelatihan kader Posbindu hari Minggu, 27 September 2020 di halaman pendopo rumah Ketua RT 1 RW 07 Mejing Wetan. Pelatihan kader diikuti kelompok Bapak, kelompok Ibu, kelompok remaja dengan jumlah 15 orang. Kader yang mengikuti pelatihan merupakan usulan dari Pengurus RT 1. Kader telah dilatih kalibrasi alat, sehigga diharapkan alat yang digunakan tetap terjamin akurasi hasilnya. Salah satu kader telah bekerja sebagai teknisi elektromedis sehingga sudah menguasai tentang kalibrasi dan perawatan peralatan Posbindu PTM. Kader akan bertugas di setiap meja pelayanan Posbindu PTM yang terbagi menjadi lima jenis pelayanan, sehingga setiap meja akan dilayani tiga kader. Foto dokumentasi pelaksanaannya dapat dilihat pada gambar 3 .

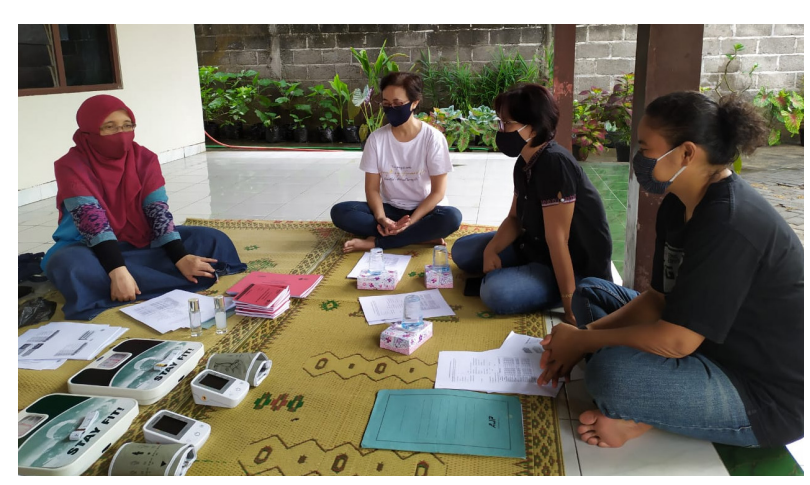

Gambar 3. Pelatihan Kader Posbindu PTM pada Kelompok Ibu 
Berikut ini karakteristik kader Posbindu yang sudah dilatih.

Tabel 2. Karakteristik Kader Posbindu PTM Mejing Wetan, Ambarketawang, Gamping, Sleman Bulan September 2020

\begin{tabular}{lcc}
\hline Karakteristik Kader & $\begin{array}{c}\text { Jumlah } \\
(\mathrm{n}=15)\end{array}$ & Persentase \\
\hline Pendidikan & & \\
$\quad$ SMA & 8 & 53,3 \\
D3 & 2 & 13,3 \\
S1 & 4 & 26,7 \\
S2 & 1 & 6,7 \\
Jenis Kelamin & & \\
Laki-laki & 7 & 46,7 \\
$\quad$ Perempuan & 8 & 53,3 \\
\hline
\end{tabular}

Karekteristik pendidikan kader kesehatan Posbindu Waras sebagian besar lulusan SMA (53,3\%) dan memiliki 1 kader lulusan S2 (6,7\%). Kader telah dilatih pengukuran tekanan darah, lingkar perut, berat badan, menghitung IMT, dan deteksi faktor risiko PTM. Setelah pelatihan, setiapkader diobservasidanmenunjukkan bahwa setiap kader terampil melakukan pengukuran tekanan darah, lingkar perut, dan berat badan, sehingga siap menyelenggarakan kegiatan Posbindu. Hal ini sesuai dengan hasil kegiatan pelatihan kader Posbindu PTM di Ranting 'Aisyiyah Ambarketawang bahwa pelatihan kader dapat meningkatkan ketrampilan kader sehingga mampu menyelenggarakan Posbindu PTM di Ranting 'Aisyiyah Ambarketawang (Sulistyaningsih \& Listyaningrum, 2020). Pelatihan kader Posbindu dilakukan untuk meningkatkan kemampuan baik pengetahuan maupun skill sehingga menumbuhkan kepercayaan diri para kader (Kusuma, Puspitaningsih, Dwisyalfina, \& Widayanti, 2018) dan kader posbindu dapat lebih tanggap terhadap masyarakat lingkungan sekitarnya terutama pada penduduk usia 15 sampai dengan 59 tahun (Indarjo, 2019). Pelatihan yang lebih intensif terhadap kader mengenai PTM dari tenaga kesehatan, penambahan kegiatan kesehatan untuk meningkatkan intensitas kehadiran warga dan kerja sama lintas sektor menjadi alternatif yang dapat diterapkan untuk penguatan program Posbindu PTM. Pelatihan dan pembentukan kader Posbindu PTM diharapkan menjadi program dari dan untuk masyarakat, sehingga masyarakat dapat secara mandiri melakukan deteksi dini (Nugraheni \& Hartono, 2018).

Penyelenggaraan Posbindu WARAS pertama kali dilaksanakan pada hari Minggu, 4 Oktober 2020 pukul 09.00-12.00 WIB di lapangan Jemparingan Mejing Wetan. Warga yang hadir 67 orang. Foto dokumentasi pelaksanaan kegiatan dapat dilihat pada gambar 4. Pelaksanaan dari Posbindu WARAS menerapkan protokol Covid-19 yaitu memakai masker, pengukuran suhu badan, menggunakan hand sanitizer, dan menjaga jarak. Kegiatan Posbindu terdiri dari 5 meja. Pelayanan yang diberikan di meja pertama yaitu registrasi dengan mengisi daftar hadir dan pembagian buku saku Posbindu. Pelayanan meja kedua adalah wawancara yaitu dengan menanyakan riwayat PTM pada keluarga maupun diri peserta, faktor risiko PTM, dan mendeteksi faktor risiko perilaku PTM antara lain adanya anggota keluarga yang merokok, konsumsi sayur dan buah, aktivitas fisik yang dilakukan, minum minuman berakhohol serta stres. Pelayanan di meja ketiga adalah pengukuran tinggi badan, berat badan, dan lingkar perut. Pelayanan di meja keempat adalah pemeriksaan tekanan darah, tekanan darah, gula darah sewaktu, kolesterol, dan asam urat. Pelayanan di meja lima adalah edukasi dan konseling kesehatan yang dilakukan oleh perawat.

Kader Posbindu WARAS sangat antusias dan kompak memberikan pelayanan di setiap mejanya dan terampil melakukan pemeriksaan kesehatan dasar. Hal ini menunjukkan bahwa pelatihan Kader Posbindu WARAS mampu meningkatkan ketrampilan dan kepercayaan diri kader (Fatmah \& Nasution, 2012). Faktor yang berhubungan dengan kinerja kader Posbindu secara simultan adalah sikap, motivasi, SDM, penghargaan, dan desain pekerjaan 90\% mempengaruhi kinerja kader Posbindu PTM. Ada hubungan positif sikap, motivasi, penghargaan, dan desain pekerjaan dengan kinerja kader Posbindu PTM dan tidak ada hubungan SDM dan peran pemangku kepentingan dengan kinerja kader Posbindu PTM (Kiting, Ilmi, \& Arifin, 2017). 


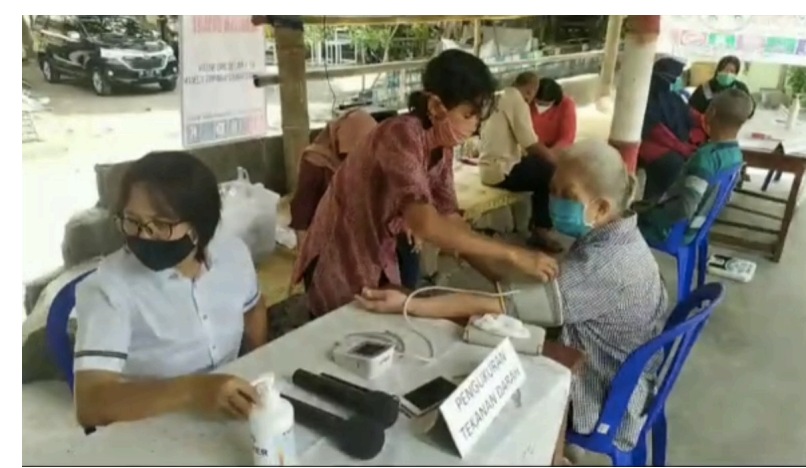

Gambar 3. Pemeriksaan Tekanan Darah pada Pelaksanaan Posbindu WARAS

Warga RT 1 Mejing Wetan memanfaatkan Posbindu untuk memantau faktor risiko PTM di era pandemi Covid-19 (Rahadjeng \& Nurhotimah, 2020). Hasil deteksi faktor risiko PTM dapat dilihat pada tabel 3 .

Tabel 3 menunjukkan bahwa faktor risiko perilaku yang paling tinggi adalah perilaku merokok, kurang aktivitas fisik (minimal 30 menit per hari atau 150 menit per minggu), dan kurang makan sayur dan buah (kurang dari 5 porsi dalam sehari atau hanya satu kali sehari). Faktor perilaku tersebut berpengaruh terhadap empat faktor metabolik kunci penyakit tidak menular, yaitu tekanan darah meningkat, kelebihan berat badan/obesitas, kadar glukosa darah yang tinggi, dan kadar kolesterol yang meningkat (Warganegara \& Nur, 2016).

Peserta Posbindu Waras yang memiliki riwayat keluarga menderita PTM sejumlah 32 orang (47,8\%), antara lain hipertensi (14 orang), jantung koroner (10 orang), diabetes melitus (4 orang), strok ( 2 orang), PPOK ( 2 orang), kanker ( 2 orang), asma ( 2 orang), dan kolesterol tinggi
(1 orang). Sebagian besar peserta memiliki riwayat keluarga menderita PTM lebih dari 1 jenis PTM (17 orang atau 25\%). Berikut ini hasil pemeriksaan kesehatan pada kunjungan pertama Posbindu WARAS.

Warga yang berkunjung ke Posbindu berdasarkan tabel 4 sebesar 49,26\%. Selain warga RT 1 Mejing Wetan, Posbindu WARAS juga dihadiri dari beberapa warga sekitar RT 1. Antusiasme warga untuk mengikuti kegiatan Posbindu WARAS dipengaruhi oleh motivasi diri untuk mengetahui status kesehatannya dan dukungan sosial antara lain dari Kepala Pedukuhan Mejing Wetan, Ketua RW, Ketua RT, dan kerja keras pengurus Posbindu WARAS. Antusiasme warga tersebut sesuai dengan Gambaran Dukungan Keluarga terhadap Pemanfaatan Posbindu Lansia di Kelurahan Karasak Kota Bandung bahwa sebagian besar keluarga memberikan dukungan penghargaan yaitu $59,7 \%$ dan instrumental sebesar 53,2\%, sedangkan keluarga yang tidak mendukung pemanfaatan posbindu lansia sebesar 53,2\%, dukungan emosional sebesar 58,4\%, dukungan informasi sebesar 81,8\%, dan dukungan jaringan sebesar 66,2\% (Bratanegara, Lukman, \& Nur Oktavia Hidayati, 2012). Keluarga merupakan bagian terkecil dalam komunitas dimasyarakat, dukungan keluarga terhadap keaktifan posbindu sangatlah penting sebagai motivasi untuk dapat mengakses fasilitas kesehatan. Hal ini sesuai dengan hasil kegiatan pengabdian kepada masyarakat (Kusuma et al., 2018) bahwa kunjungan warga ke Posbindu dipengaruhi motivasi diri dan dukungan sosial.

Tabel 3. Faktor Risiko Perilaku PTM Peserta Posbindu PTM Mejing Wetan, Ambarketawang, Gamping, Sleman Bulan Oktober 2020

\begin{tabular}{llcc}
\hline No & \multicolumn{1}{c}{ Faktor Risiko Perilaku PTM } & $\begin{array}{c}\text { Frekuensi } \\
(\mathrm{n}=67)\end{array}$ & Persentase \\
\hline 1. & \multicolumn{1}{c}{ Ada anggota keluarga yang merokok di dalam rumah } & 18 & 26,9 \\
2. & Kurang makan sayur dan buah (kurang dari 5 porsi dalam sehari \\
& atau hanya 1x sehari) & 14 & 20,9 \\
3. Kurang aktivitas fisik (minimal 30 menit per hari atau 150 menit per & 15 & 22,4 \\
& & & \\
minggu) & Konsumsi minuman beralkohol & 1 & 1,5 \\
5. Stres (tegang, takut, cemas, mudah marah, sedih, dan putus asa) & 3 & 4,5 \\
\hline
\end{tabular}


Tabel 4. Hasil Pemeriksaan Fisik dan Laboratorium untuk Deteksi Faktor Risiko PTM Peserta Posbindu PTM Mejing Wetan, Ambarketawang, Gamping, Sleman Bulan Oktober 2020

\begin{tabular}{|c|c|c|}
\hline Hasil Pemeriksaan & Jumlah & Persentase \\
\hline \multicolumn{3}{|l|}{ Kepesertaan } \\
\hline Jumlah Anggota Semua (S) & 136 & \\
\hline Jumlah Anggota Datang (D) & 67 & \\
\hline Kunjungan D/S (\%) & & 49,26 \\
\hline \multicolumn{3}{|l|}{ Index Massa Tubuh (IMT) } \\
\hline Normal $(\leq 23)$ & 26 & 38,81 \\
\hline Tidak Normal $(>23)$ & 41 & 61,19 \\
\hline \multicolumn{3}{|l|}{ Lingkar Perut } \\
\hline Normal $(\mathrm{L}<90 \mathrm{Cm}, \mathrm{P}<80 \mathrm{Cm})$ & 31 & 46,27 \\
\hline Tidak Normal (Laki-laki $\geq 90 \mathrm{~cm}$, Perempuan $\geq 80 \mathrm{Cm}$ ) & 36 & 53,73 \\
\hline \multicolumn{3}{|l|}{ Tekanan Darah } \\
\hline Normal $(<140 / 90)$ & 45 & 67,16 \\
\hline Tidak Normal ( $\geq 140 / 90)$ & 22 & 32,84 \\
\hline \multicolumn{3}{|l|}{ Gula Darah Sewaktu } \\
\hline Yang Diperiksa & 21 & \\
\hline Normal $(<200)$ & 20 & 95,24 \\
\hline Tidak Normal $(\geq 200)$ & 1 & 4,76 \\
\hline \multicolumn{3}{|l|}{ Kolesterol } \\
\hline Yang Diperiksa & 8 & \\
\hline Normal $(<190)$ & 2 & 25,00 \\
\hline Tidak Normal $(\geq 190)$ & 6 & 75,00 \\
\hline \multicolumn{3}{|l|}{ Asam Urat } \\
\hline Yang Diperiksa & 21 & \\
\hline Normal $(<7)$ & 19 & 90,48 \\
\hline Tidak Normal ( $\geq 7$ ) & 2 & 9,52 \\
\hline
\end{tabular}

Hasil pemeriksaan pada tabel 4 diperoleh sebagian besar $(51,19 \%)$ peserta Posbindu memiliki IMT yang tidak normal sebesar $(>23)$ sebesar 41orang. IMT merupakan alat ukur yang sederhana dalam pemantauan status gizi orang dewasa terkait dengan kelebihan dan kekurangan berat badan. IMT dapat menggambarkan kadar adipositas atau akumulasi lemak dalam tubuh seseorang. Lemak yang berlebihan dalam tubuh dapat menyebabkan timbulnya risiko terhadap kesehatan. Salah satu risiko yang dihadapi adalah obesitas atau kegemukan. IMT berhubungan dengan tekanan darah sistol maupun diastolik terutama pada lansia, yang akan mempengaruhi terjadinya hipertensi (Ningtyas, Meri, \& Rizqiea Noerma Shovie, 2020).
Lingkar perut sebagian besar peserta Posbindu (53,73\%) adalah tidak normal. Lingkar perut yang tidak normal mempunyai risiko yang sama dengan IMT yang tidak normal yaitu dapat meningkatkan tekanan darah. Lingkar perut yang tidak normal menggambarkan kecenderungan terjadinya obesitas (Sari, Lipoeto, \& Herman, 2016).

Walaupun sebagian IMT tidak normal, tetapi tekanan darah sebagian besar $(67,16 \%)$ peserta Posbindu normal $(<140 / 90)$, sisanya mengalami hipertensi. Peserta Posbindu yang memiliki riwayat hipertensi sebesar 14 orang. Kondisi tersebut harus menjadi perhatian besar karena hipertensi sebagai faktor pencetus strok dengan hasil gangguan fisiologis yang 
terjadi pada pengaturan aliran darah sehingga menyebabkan hipertensi diantaranya gangguan pada kardiak output dan resistensi perifer, gangguan pada sistem renin-angiotensin, dan gangguan pada sistem saraf otonom. Terdapat hubungan antara onset dari hipertensi dan komplikasi hipertensi. Selama jangka waktu yang panjang tersebut, serangkaian perubahan terjadi dalam sistem kardiovaskular termasuk sirkulasi serebral. Perubahan yang terjadi seperti renovasi vaskular, peradangan, stres oksidatif, dan disfungsi barorefleks berkontribusi dalam patogenesis strok yang disebabkan oleh hipertensi (Yonata \& Pratama, 2016). Penderita hipertensi mempunyai risiko 6,18 kali lebih besar terjadinya strok (Khairatunnisa \& Sari, 2017). Terdapat dua orang peserta Posbindu WARAS yang mempunyai riwayat keluarga strok, sehingga faktor risiko tersebut perlu dikelola dengan baik terutama yang sudah menderita hipertensi.

Hasil pemeriksaan gula darah sewaktu peserta Posbindu WARAS adalah sebagian besar normal $(95,24 \%)$, hanya ada satu dari 21 orang yang diperiksa yang menunjukkan kondisi tidak normal. Walaupun demikian, kondisi tersebut harus dikelola dengan baik mengingat ada empat orang peserta Posbindu WARAS yang mempunyai riwayat keluarga Diabetes Mellitus (DM). Orang yang memiliki riwayat keluarga DM mempunyai risiko sebesar 6,48 kali lebih besar terkena diabetes melitus dibandingkan orang yang tidak memiliki riwayat keluarga DM (OR: 6,48; 95\% CI: 2,08 - 20,21). Perlunya pengurangan pola makan yang kurang sehat dan peningkatan aktivitas fisik yang cukup bagi masyarakat khususnya yang memiliki riwayat keluarga DM untuk mencegah terjadinya kejadian DM (Amalia, 2014).

Kolesterol peserta Posbindu WARAS dari delapan orang yang diperiksa, enam (75\%) diantaranya kolestreol tinggi dan ada satu orang yang mempunyai riwayat keluarga kolesterol tinggi. Kolesterol adalah suatu zat lemak yang beredar dalam darah, diproduksi oleh hati dan sangat diperlukan oleh tubuh. Darah mengandung $80 \%$ kolesterol yang diproduksi oleh tubuh sendiri dan $20 \%$ berasal dari makanan. Meningkatnya kolesterol lebih banyak karena dipengaruhi oleh pola makan yang tidak seimbang (Ouslan, 2016). Kolesterol berlebih akan menimbulkan masalah terutama pada pembuluh darah jantung dan otak. Peningkatan kadar kolesterol seiring dengan bertambahnya risiko penyakit jantung koroner.

Hasil pemeriksaan asam urat peserta Posbindu WARAS menunjukkan sebagian besar normal $(90,48 \%)$. Penyakit gout (asam urat) merupakan penyakit yang disebabkan oleh tumpukan kristal asam urat pada jaringan, terutama pada jaringan sendi. Gout berhubungan erat dengan gangguan metabolisme purin yang memicu peningkatan kadar asam urat dalam darah (hiperurisemia), yaitu jika kadar asam urat dalam darah lebih dari 7,5 mg/dl. Salah satu faktor yang mempengaruhi adalah pola makan yang salah yaitu banyak mengonsumsi makanan tinggi purin (Amalia, 2014).

Posbindu PTM merupakan salah satu Upaya Kesehatan Berbasis Masyarakat (UKBM) sehingga peran serta masyarakat sangat diperlukan (Rahadjeng \& Nurhotimah, 2020). Pemanfaatan Posbindu PTM berhubungan dengan pencegahan PTM (Ningtyas et al., 2020). Keberlanjutan Posbindu WARAS menjadi hal yang penting untuk dilaksanakan setelah pengabdian masyarakat dari Universitas 'Aisyiyah Yogyakarta selesai dilaksanakan. Kader Posbindu WARAS secara mandiri dapat mengelola Posbindu sehingga dapat menyelenggarakan kegiatan Posbindu secara rutin setiap bulan selama bulan Oktober sd. Desember 2020. Rutinitas pelaksanaan Posbindu PTM sangat mempengaruhi keberhasilan deteksi faktor risiko PTM. Hal ini diperkuat dengan hasil analisis implementasi Posbindu PTM Kecamatan Banguntapan Bantul belum berjalan secara optimal dikarenakan pelaksanaan belum rutin, kemitraan dengan lintas sektor terbatas, dan pelaksanaan tahapan 5 layanan belum optimal (Pranandari, 2017). Peran lintas sektor diperlukan agar keberlanjutan Posbindu PTM dan peran kader dalam deteksi dini semakin meningkat (Lestari, Warseno, Trisetyaningsih, Rukmi, \&Suci, 2020). Kurangnya kerja samalintas sektor, kelengkapan prasarana yang mendukung seperti alat cek gula darah, alat cek kolesterol, dan alat cek IVA, monitoring dan evaluasi yang dilakukan oleh instansi Dinas Kesehatan dan aparat desa setempat (baik itu RW, kelurahan, 
atau kecamatan) (Nugraheni \& Hartono, 2018), pengetahuan kader yang kurang dan keterbatasan pembiayaan akan mempengaruhi pelaksanaan Posbindu kurang optimal (Sicilia, Fatwa, \& Retna, 2018). Kemandirian warga RT 1 Mejing Wetan dalam menyediakan pembiayaan untuk pemeriksaan laboratorium di Posbindu WARAS patut dipertahankan agar dapat menjamin keberlangsungan kegiatan Posbindu.

Keberhasilan dalam berkomunikasi sangat mempengaruhi implementasi kebijakan program Posbindu PTM di Puskesmas Sinar Baru pada tahun 2018 (Sudracun, Wati, \& Fikri, 2020), dengan demikian, saluran komunikasi dengan warga RT 1 Mejing Wetan harus tetap dibangun agar pelaksanaan kegiatan Posbindu terus konsisten. Upaya peningkatan cakupan kunjungan juga perlu terus dilakukan, salah satunya melalui kunjungan Kader Posbindu WARAS kepada lansia ataupun warga penderita komorbid (Pranandari, 2017). Pemberdayaan Kader Posbindu dapat dilakukan dengan peningkatan kader aktif, tersedianya media promosi, peningkatan tentang mencegahan dan penanganan masalah kesehatan lansia, manajemen komplementer, deteksi dini pemeriksaan PTM dan laboratorium sederhana, penanaman obat keluarga (herbal) serta kader mampu memproduksi bahan herbal berupa sirup, serbuk, ekstrak, dan minyak atsiri (Hartiti, 2017).

\section{SIMPULAN}

Simpulan program pengabdian ini adalah sikap yang mendukung dari Pengurus RT dan segenap tokoh masyarakat terhadap pembentukan Posbindu PTM, susunan kepengurusan Posbindu PTM telah terbentuk dan kader Posbindu PTM sehingga dapat melaksanakan peran dan tugasnya dalam pelaksanaan Posbindu PTM Dasar. Terbentuknya Posbindu PTM Dasar yang dilaksanakan bersamaan dengan arisan rutin ibu-ibu setiap hari Minggu pekan pertama pukul 09.00 WIB di lapangan Jemparingan Mejing Wetan. Posbindu WARAS dapat mengetahui riwayat PTM pada keluarga maupun diri peserta, melayani pemeriksaan kesehatan dan laboratorium dasar sehingga dapat mendeteksi faktor risiko perilaku PTM maupun faktor risiko PTM.

Pengurus Posbindu PTM diharapkan dapat melanjutkan kerja sama dengan UNISA Yogyakarta untuk menyelenggarakan pelatihanpelatihan deteksi faktor risiko PTM, antara lain SADARI maupun pelatihan konseling tindak lanjut faktor risiko PTM. Warga diharapkan datang secara rutin ke Posbindu PTM sehingga dapat monitor faktor risiko PTM, makan sayur dan buah (minimal 5 porsi dalam sehari), aktivitas fisik (minimal 30 menit per hari atau 150 menit per minggu). Bagi warga yang mempunyai faktor risiko diharapkan dapat menindaklanjuti dengan datang ke fasilitas kesehatan tingkat Pertama.

\section{PERSANTUNAN}

Tim pelaksana kegiatan mengucapkan terima kasih kepada Rektor Universitas 'Aisyiyah Yogyakarta dan Ketua LPPM yang telah memberikan dukungan pendanaan untuk pelaksanaan program pengabdian ini. Ucapan terima kasih juga disampaikan kepada Ketua RT 1 RW 07 Mejing Wetan, dan Pengurus Posbindu WARAS yang telah menjadi mitra yang baik dalam pelaksanaan program pengabdian. Apresiasi yang tinggi terhadap semua warga yang telah berpartisipasi mengikuti kegiatan Posbindu PTM.

\section{REFERENSI}

Amalia, R. F. (2014). Faktor Risiko Kejadian Diabetes Melitus pada Lansia di Puskesmas Kecamatan Mampang Prapatan Jakarta Selatan Tahun 2014. Jakarta, Indonesia. Retrieved from http://lib. ui.ac.id/naskahringkas/2016-06/S54936-Riska Farina Amalia

Bratanegara, A. S., Lukman, M., \& Nur Oktavia Hidayati. (2012). Gambaran Dukungan Keluarga terhadap Pemanfaatan Posbindu Lansia di Kelurahan Karasak Kota Bandung.Jurnal Unpad, Vol. 1(1), 1-15. 
Dinas Kesehatan Daerah Istimewa Yogyakarta. (2020). Profil Kesehatan Daerah Istimewa Yogyakarta Tahun 2019. Yogyakarta.

Dinas Kesehatan Kabupaten Sleman. (2020). Profil Kesehatan Kabupaten Sleman Tahun 2020. Sleman, DIY.

Direktorat Jenderal Pencegahan dan Pengendalian Penyakit. (2019). Buku Pedoman Penyakit Tidak Menular.

Direktorat Jenderal Pencegahan dan Pengendalian Penyakit Kemenkes RI. (2019). Buku Pedoman Penyakit Tidak Menular. Kementerian Kesehatan RI. Jakarta, Indonesia.

Fatmah, \& Nasution, Y. (2012). Peningkatan Pengetahuan dan Keterampilan Kader Posbindu dalam Pengukuran Tinggi Badan Prediksi Lansia, Penyuluhan Gizi Seimbang, dan Hipertensi Studi di Kecamatan Grogol Petamburan, Jakarta Barat. Media Medika Indonesiana, 46, 61-68.

Hartiti, T. (2017). Pemberdayaan Kader Posbindu Lansia sebagai Upaya Peningkatan Kualitas Hidup Lansia di Desa Kangkung Demak. Prosiding Seminar Nasional 2014.

Indarjo, S. (2019). Upaya Pelatihan Pos Pembinaan Terpadu Penyakit Tidak Menular (Posbindu PTM) pada Kader Posyandu di Desa Kalikayen, Kec. Ungaran Timur, Kab. Semarang. Jurnal Abdimas, 23(2), 134-138.

Kemenkes RI. (2012). Petunjuk Teknis Pos Pembinaan Terpadu Penyakit Tidak Menular (Posbindu PTM). Ditjen Pengendalian Penyakit dan Penyehatan Lingkungan, Kementerian Kesehatan RI. Jakarta, Indonesia.

Kementerian Kesehatan Badan Penelitian dan pengembangan Kesehatan. (2018). Hasil Utama Riset Kesehata Dasar (RISKESDAS) 2018. Jakarta, Indonesia.

Kementerian Kesehatan Republik Indonesia. (2013). Buku Monitoring Faktor Risiko Penyakit Tidak Menular. Jakarta, Indonesia.

Kementerian Kesehatan Republik Indonesia. (2020). Profil Kesehatan Indonesia Tahun 2019. Kementrian Kesehatan Republik Indonesia. Jakarta, Indonesia.

Khairatunnisa, \& Sari, D. M. (2017). Faktor Risiko yang Berhubungan dengan Kejadian Stroke pada Pasien di RSU H. Sahudin Kutacane Kabupaten Aceh Tenggara. Jurnal JUMANTIK, 2(1), 60-70. Retrieved from http://jurnal.uinsu.ac.id/index.php/kesmas/article/view/962/766

Kiting, R. P., Ilmi, B., \& Arifin, S. (2017). Faktor yang Berhubungan dengan Kinerja Kader Posbindu Penyakit Tidak Menular. Jurnal Berkala Kesehatan, 1(2), 106. https://doi.org/10.20527/jbk. v1i2.3149

Kusuma, Y. L. H., Puspitaningsih, D., Dwisyalfina, A., \& Widayanti, E. (2018). Pembentukan Program Pos Pembinaan Terpadu (Posbindu) Penyakit Tidak Menular (PTM) dengan Memanfaatkan Dana Desa Pemerintah Desa Ngrowo Kecamatan Bangsal - Mojokerto. Jurnal Pengabdian Masyarakat Kesehatan, 4(2), 68-75. https://doi.org/10.33023/jpm.v4i2.190

Lestari, R., Warseno, A., Trisetyaningsih, Y., Rukmi, D. K., \& Suci, A. (2020). Pemberdayaan Kader Kesehatan dalam Mencegah Penyakit Tidak Menular melalui Posbindu PTM. Adimas : Jurnal Pengabdian Kepada Masyarakat, 4(1), 48. https://doi.org/10.24269/adi.v4i1.2439

Mahdur, R. R., \& Sulistiadi, W. (2020). Evaluasi Program Pos Pembinaan Terpadu Penyakit Tidak Menular (Posbindu PTM). Jurnal Ilmiah Kesehatan Masyarakat, 12(1), 43-49.

Ningtyas, M. S., Meri, O., \& Rizqiea Noerma Shovie. (2020). Hubungan Pemanfaatan Posbindu dengan Pencegahan Penyakit Tidak Menular (PTM) pada Masyarakat di Posbindu Kasih Bunda Desa Klumprit, 38. 
Nugraheni, W. P., \& Hartono, R. K. (2018). Strategi Penguatan Program Posbindu Penyakit Tidak Menular di Kota Bogor. Jurnal Ilmu Kesehatan Masyarakat, 9(3), 198-206. https://doi.org/https://doi. org/

Pranandari, L. L. (2017). Analisis Implementasi Program Pos Pembinaan Terpadu Penyakit Tidak Menular (Posbindu PTM) di Kecamatan Banguntapan Kabupaten Bantul. Jurnal Kesehatan Masyarakat (e-Journal), 5(4), 76-84.

Rahadjeng, E., \& Nurhotimah, E. (2020). Evaluasi Pelaksanaan Posbindu Penyakit Tidak Menular (Posbindu PTM) di Lingkungan Tempat Tinggal. Jurnal Ekologi Kesehatan, 19(2), 134-147. https://doi.org/10.22435/jek.v19i2.3653

Sari, M. K., Lipoeto, N. I., \& Herman, R. B. (2016). Hubungan Lingkar Abdomen (Lingkar Perut) dengan Tekanan Darah. Jurnal Kesehatan Andalas, 5(2), 456-461. Retrieved from http://juke.kedokteran. unila.ac.id/index.php/majority/article/view/1030/824

Sicilia, G., Fatwa, D., \& Retna, P. (2018). Evaluasi Kualitatif Program Penyakit Tidak Menular Berbasis Posbindu di Wilayah Kerja Puskesmas Muara Bungo I. Jurnal Kebijakan Kesehatan Indonesia: JKKI, 7(2), 88-92.

Sudracun, S., Wati, M., \& Fikri, Z. (2020). Implementasi Kebijakan Program Pos Pembinaan Terpadu Penyakit Tidak Menular (Posbindu PTM) di Puskesmas Sinar Baru pada Tahun 2018. JIAP (Jurnal Ilmu Administrasi Publik), 8(2), 368. https://doi.org/10.31764/jiap.v8i2.2738

Sulistyaningsih, \& Listyaningrum, T. H. (2020). Pelatihan dan Pembentukan Posbindu Penyakit Tidak Menular (PTM) 'Aisyiyah Ranting Ambarketawang. Jurnal Pengabdian Kepada Masyarakat, 4(2), 174-185.

Warganegara, E., \& Nur, N. N. (2016). Faktor Risiko Perilaku Penyakit Tidak Menular. Majority, 5(2), 88-94. Retrieved from http://juke.kedokteran.unila.ac.id/index.php/majority/article/ view/1082/922:

Yonata, A., \& Pratama, A. S. P. (2016). Hipertensi sebagai Faktor Pencetus Terjadinya Stroke. Majority, 5(3), 17-21. Retrieved from http://juke.kedokteran.unila.ac.id/index.php/majority/article/ view/1030/824 